\title{
TOWARDS A WEB-BASED HIERARCHICAL GOAL SETTING INTERVENTION FOR HIGHER EDUCATION
}

\author{
Felix Weber, Jana Kernos, Mae Grenz and Jueun Lee \\ Osnabrück University, Germany
}

\begin{abstract}
In this paper we present the current state of a digital goal-setting intervention for higher education, which is based on the concept of hierarchical goal systems (HGS). Findings from organizational psychology, motivational psychology and educational psychology related to goals, self-regulated learning and goal systems are covered as a theoretical background. Subsequently, hierarchical goal systems are introduced conceptually and the concrete implementation and the essential functions of the digital HGS intervention are presented. Next, the current state of the development process and four studies currently in progress are briefly summarized. The studies are designed to answer the following research questions: How can students be supported in the discovery of personally relevant educational goals? How can students be supported in the construction of hierarchical goal systems directed towards such personally relevant educational goals? The paper concludes with an outlook on the benefits between students and researchers in the upcoming field study with the digital goal setting intervention.
\end{abstract}

\section{KEYWORDS}

Hierarchical Goal Systems, Goal Hierarchies, Self-Regulated Learning, Goal Setting, Higher Education, Digital Assistants

\section{INTRODUCTION}

There are at least three reasons why goals are interesting objects of investigation in educational research. The first is that they can be understood as a concrete manifestation of motivation. Humans are more likely able to elaborate on their goals than on abstract motivational dispositions, while goals can shed light onto the motivational dispositions. A second reason why goals are of significant relevance in the context education is, that goal settings has been shown to affect a broad variety of variables relevant for learning, such as activity, academic performance, well-being and vitality (Locke and Latham, 2002, 2019; Morisano, 2013). A third reason is, that considering goals as "internal representations of desirable states" (Vancouver and Austin, 1996), almost every human (learning) behavior can be viewed as being goal-directed. Consequently goal change has the potential to lead to behavior change.

Classical goal setting research originating from organizational psychology showed that the right degree of challenge has remarkable effects on performance (Locke and Latham, 1990, 2002, 2019). The more challenging the goal, the higher is the performance until the threshold of subjective ability to is exceeded. Beyond this point, performance rapidly decreases. In the domain of higher education these findings are essential because students need to find personal goals with the right degree of challenge.

More recent findings have shown correlations between motivation and well-being. For instance Ryan and Deci have outline a taxonomy of motivation and self-regulation styles in their self-determination theory (Deci and Ryan,1985; Ryan and Deci, 2017). SDT distinguishes a continuum between amotivation, different stages of external motivation and intrinsic motivation. The process of internalization of goals in this model can be promoted by the personal importance, self-endorsement, self-congruence of the goal and personal interest in the goal. This indicates that guiding students in the development of personally meaningful goals can to an increase intrinsic motivation, which is beneficial for learning and well-being. 
Self-regulated learning is a conceptualization of learning, which is theoretically supported by a variety of theoretical frameworks, ranging from operant, social cognitive to cognitive constructivist perspectives (Zimmerman, 1989). A core element of self-regulated learning is the active role learners play by regulating their behavior. Cyclic models of self-regulated learning assume iterative strategic loops (Figure 1) with phases of planning, acting and reflecting learning processes (Zimmerman, 1989, 1990). In such models, individual learning goals serve a foundation for planning and benchmarks for evaluation.

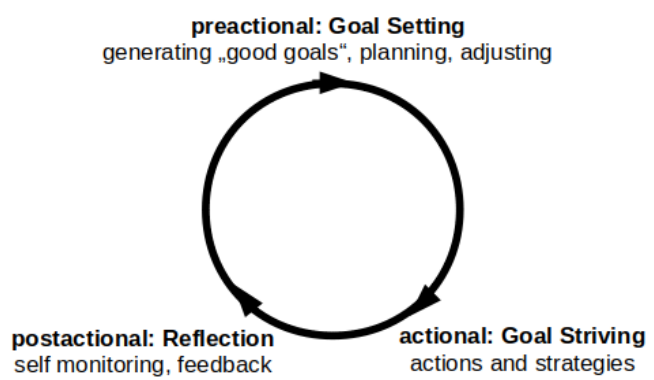

Figure 1. An iterative strategic loop is at the core of cyclic models of self-regulative learning. It can be assumed that learners in higher education experience phases and loops on various time levels and in parallel in various contexts

Goal clarification and related activities, such as elaboration and planning can lead to progress in terms of goal-achievement on a long-term perspective. Elaboration on goals and intensive writing about goals and ideal future can significantly increase academic performance (Morisano, 2008; Schippers et. al 2020). From these findings it can be concluded that students can benefit from intensive thinking, writing or digitally working on their personal educational goals. Hence, a digital assistant for guiding students through processes of goal setting, goal striving and reflecting about goal progress and goal achievement in higher education has the potential to accelerate individual academic progress.

\section{HIERARCHICAL GOAL SETTING IN A DIGITAL STUDY ASSISTANT}

In recent years there is a trend in goal setting research towards the study of goal systems and the relationships between goals (Kung \& Scholer 2018, 2020). Goals with synergistic relationships can be modeled as coherent goal systems. Technically, hierarchical goal systems (HGS) are tree-shaped goal system, in which each goal has exactly one superordinate goal, except for the root goal. It has been shown that the structure of goal systems is a predictor for peoples' ability to choose the right means for goal pursuit and that a tree-shaped structure of goal systems increases tractability for humans (Bourgin et al., 2017). Hence, hierarchical representations seem to be compatible with mental models of goal systems.

Compared to other types of goal systems representations, such as sequential models and network models, hierarchical goal systems show at least three distinguishing properties concerning self-regulation. Firstly, every actionable goal contributes to a superordinate goal, which highlights its purpose and may increase motivation. Secondly, in the actional phase of goal-striving, action selection from the bottom layer is simple and a balance between guidance and free choice is given. Thirdly, in phases of reflection, goal progress can be evaluated based on quantity of achieved subgoals, and alternative actions and strategies can be dynamically added. The cost for these functional advantages is the effort of transforming the goal-related problem domain into a strict hierarchical schema. Participants in our studies have reported the translation to be especially challenging for subgoals contributing to more than one superordinate goal. Once a higher order goal and the problem domain has been modeled as HGS, goal pursuit is promoted by the former mechanisms. 

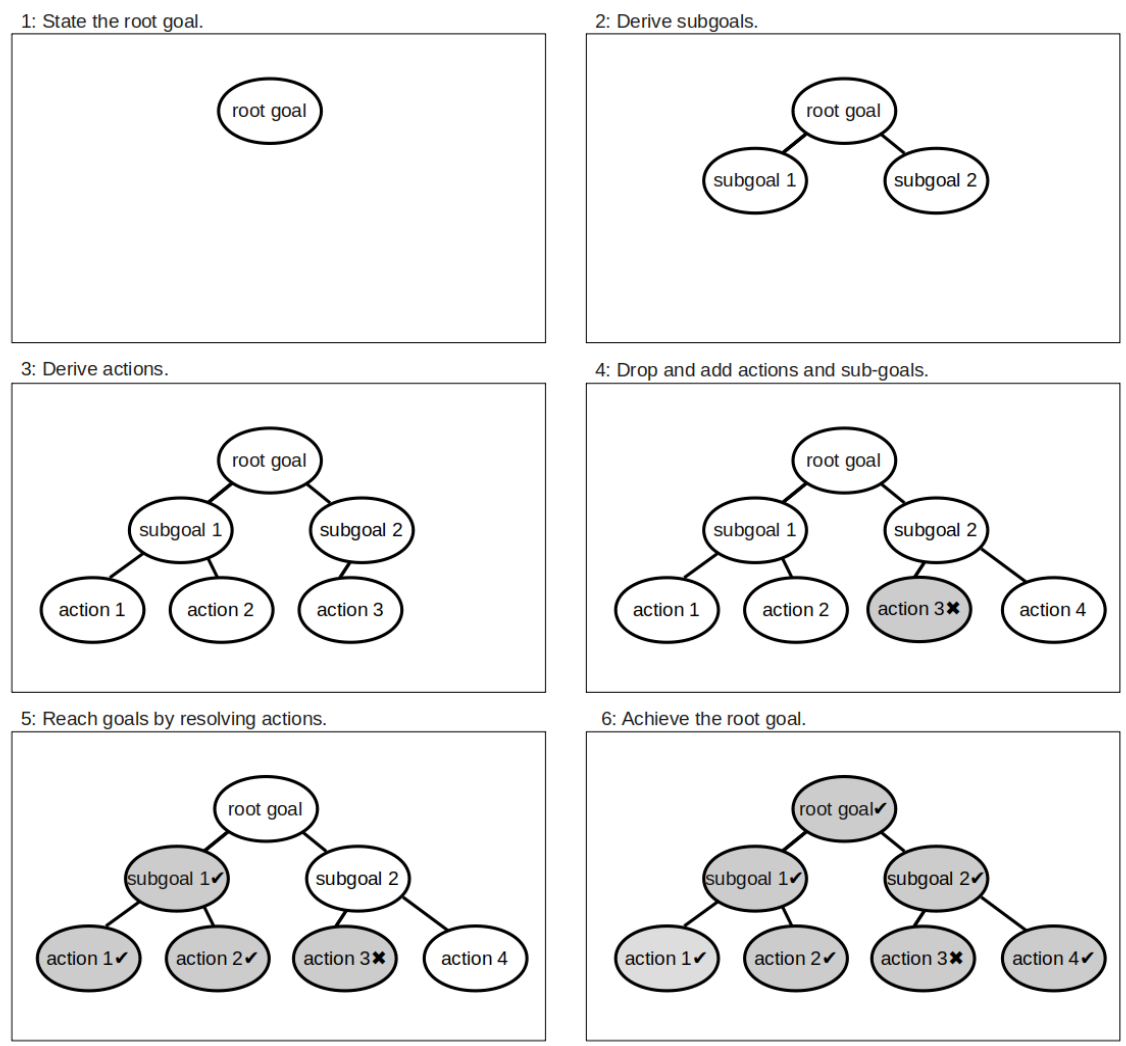

Figure 2. User interactions with a hierarchical goal system during its' life cycle

Our aim is to support students in the development of skills in self-organization and self-regulated learning. In their everyday life, university students learn on a concrete curricular level, but also on a meta-level of self-organization. They have to organize and prioritize tasks and plan and individualize their study paths. The current research prototype of a digital tool for hierarchical goal setting supports students by the following mechanisms:

- Students are encouraged or nudged to think about abstract personal goals and to define them. This functionality can lead to more motivation caused by meaningful educational goals.

- Connections between personally meaningful long-term goals to concrete tasks in everyday-life become transparent. This helps to activate and motivate for the concrete learning tasks ahead.

- The resulting personal educational root goals and maintained in the study assistant over time. This externalized memory supports goal stability and can increase attentional and volitional focus.

- Students are regularly nudged to think about new sub-goals, actions and strategies suitable to achieve personal root goals. This can lead to the refinement of suitable metacognitive strategies.

- Task selection and prioritization is done by picking tasks from the bottom layer of a hierarchical goal system. Simplified selection and prioritization reduces mental costs.

- Reflecting and evaluating goal progress, applied actions and strategies based on the goal system representation in the assistant leads to self-realization and learning on a metacognitive level.

Figure 2 illustrates how hierarchical goal systems can serve to bridge the gap between possibly abstract and distal root goals and concrete actions.

\subsection{Current State of the Development Process}

In a paper-pencil prestudy and a digital pilot study data was collected and analyzed exploratively. This helped us to identify two central challenges. The first is, that is a non-trivial task for students to spontaneously identify personal goals suitable as root goals. Consequently, we are developing and testing 
procedures that support students in discovering and developing personally relevant, distal educational goals. The second challenge is to develop an intuitive interface that makes it easy for students to construct hierarchical goal systems based on the root goals. To solve the second challenge, we have implemented four different types of hierarchical visualizations which are investigated regarding usability, user experience and personal preferences resulting from character traits. The following four studies are currently in progress.

\subsubsection{Qualitative Usability and UX Think-aloud}

In the first study, user experience and usability is optimized by testing the software with help of Think-Aloud Method (Albert \& Tullis, 2008, p. 103). The TA-Method is supposed to provide detailed qualitative feedback in each step for each of four possible visual representations currently implemented in the software. Four subjects are randomly assigned to one visualization type, and instructed to verbalize the actions, and thoughts, during use the software. This method is supposed to shape the usability of the visual representation of the digital assistant and to provide insights about functional differences between visualizations.

\subsubsection{Quantitative Usability and UX}

In the second study, the four visual representations are examined with quantitative methods. Therefore, 48 students in four conditions go through a pseudo-randomized between-group experiment with a fixed scenario. In this study we shall compare their performance measuring the amount of time they spend on the task and the amount of clicks and errors they make. Additionally we want to measure self-reported efficiency, effectiveness and satisfaction with the help of System Usability Scale (Brooke, 1996) and After-Task Questionnaire (Lewis, 1991, Albert \& Tullis, 2008, pp. 128-129). This study seeks to compare the success and satisfaction level of students using different visual implementations of the hierarchical goal system. With the help of received data we want to find out which visual representation is more suitable for the digital study assistant to design its interface in the most suitable and intuitive way.

\subsubsection{Effects of OCEAN Personality Traits}

In the third study, we aim to investigate the effects of OCEAN or Big Five personality traits (Goldberg, 1990; McCrae \& Costa 1987) on the preference for a visualization type. Furthermore, participants are asked to evaluate the perceived complexity of the visualizations on a multi-item Likert scale and construct a personal hierarchical goal system with a randomly assigned visualization. The System Usability Scale (Brooke, 1996) is used to measure the usability of the intervention and a ranking of the visualizations by the participants allow to measure preferences for the visualizations types. This study explores a possible prediction of the preferred visualization type by the OCEAN personality traits. Since the web-based intervention is driven by personal goals, the visualization should ideally fit the individual preferences to allow for a more pleasant experience, increasing the motivation to continuously use the intervention.

\subsubsection{Root Goal Elicitation with Priming}

The fourth study uses priming to elicit goals with specific characteristics. Goals' self-concordance is not only a positive predictor of persistent effort in goal pursuit but also associated with increased happiness and goal attainment in the longer term (Sheldon, 2014). This study aims to investigate whether the priming of different motivations based on the self-determination continuum (intrinsic, identified, introjected, extrinsic motivation and amotivation) can influence the self-concordance of subsequently elicitated goals. In addition, it will be examined how the priming effect influences other goal characteristics such as goal specificity. This study hypothesizes that motivations that are intrinsically regulated are positively associated with higher goal concordance, thus students primed with stimuli related to intrinsic motivation select more self-concordant goals than those primed with stimuli related to extrinsic motivation or amotivation. In a within-subjects online experiment, participants will be assigned to each of the five conditions (intrinsic, identified, introjected, extrinsic motivation and amotivation) in pseudo-random order and asked to complete a writing task as priming stimulus. In a second task they are asked to formulate a personal academic goal. The goal characteristics questionnaire (Iwama et al., 2019) is used to measure the characteristics of resulting goals. The goal of this study is to gain insights how to build a priming task to elicit self-concordant goals as root goals for the hierarchical goal setting intervention. 


\section{OUTLOOK}

The two most important intermediate goals of the outlined research are a) to build a hierarchical goal setting intervention that improves students' academic life and b) to implement a field study which allows the collection of hierarchical goal systems in a natural environment. To convince students to use the hierarchical goal setting intervention, we are working on an attractive interface with low interaction costs and high availability, embedded into the local learning management system. Goal characteristics will be measured and transparently displayed to students, enriched with background information. In this way students can benefit from scientific insights into human goal setting and goal pursuit and at the same time valuable data is generated which can promote scientific progress.

\section{ACKNOWLEDGEMENT}

The authors would like to express their very great appreciation to D.B., who did a great job implementing the software and took care of countless technical wishes of the authors to make all of the studies possible. Thank you!

\section{REFERENCES}

Albert, W., \& Tullis, T. (2008). How to identify an issue. In Measuring the User Experience: Collecting, Analyzing, and Presenting Usability Metrics (Interactive Technologies) (1st ed., p. 103). Morgan Kaufmann.

Albert, W., \& Tullis, T. (2008). Post-task ratings. In Measuring the User Experience: Collecting, Analyzing, and Presenting Usability Metrics (Interactive Technologies) (1st ed., pp. 128-129). Morgan Kaufmann.

Bourgin, D., Lieder, F., Reichman, D., Talmon, N., \& Griffiths, T. L. (2017). The Structure of Goal Systems Predicts Human Performance. Proceedigns of the 39th Annual Meeting of the Cognitive Science Society, 1660-1665.

Brooke, J. (1996). SUS: A quick and dirty usability scale. In P. W. Jordan, B. Thomas, B. A. Weerdmeester, \& I. L. McClelland (Eds.), Usability evaluation in industry. London: Taylor \& Francis.

Cheung, E. (2004). Goal Setting as Motivational tool in Student's Self-regulated Learning. Educational Research Quarterly, 27(3), 3-9.

Deci, E. L. and Ryan, R. M. (1985) Intrinsic Motivation and Self-Determination in Human Behavior, Intrinsic Motivation and Self-Determination in Human Behavior. doi: 10.1007/978-1-4899-2271-7.

Ryan, R. M., Deci, E. L. and (Eds.) (2017) Self-Determination Theory: Basic Psychological Needs in Motivation, Development, and Wellness, Self-Determination Theory: Basic Psychological Needs in Motivation, Development, and Wellness. Edited by R. M. Ryan and E. L. Deci. Guilford Press. doi: 10.1521/978.14625/28806.

Doran, G. T. (1981) 'There's a S.M.A.R.T way to write management's goals and objectives', Management Review, 70(11), pp. 35-36.

Ehrlich, C. (2012) 'Be careful what you wish for but also why you wish for it - Goal-striving reasons and subjective well-being', Journal of Positive Psychology, 7(6), pp. 493-503. doi: 10.1080/17439760.2012.721382.

Elliot, A. J. and Thrash, T. M. (2001) 'Achievement Goals and the Hierarchical Model of Achievement Motivation', Educational Psychology Review, 13(2), pp. 139-156.

Goldberg, L. R. (1990). Personality processes and individual differences - An Alternative " Description of Personality ": The Big-Five Factor Structure. Journal of Personality and Social Psychology, 59(6), 1216-1229.

Iwama, G., Wirzberger, M. and Lieder, F. (2019) 'The Goal Characteristics (GC) questionnaire: A comprehensive measure for goals , content , attainability, interestingness, and usefulness', (July). doi: 10.13140/RG.2.2.24237.84961.

Komarraju, M., Karau, S. J., Schmeck, R. R., \& Avdic, A. (2011). The Big Five personality traits, learning styles, and academic achievement. Personality and Individual Differences, 51(4), $472-477$. https://doi.org/10.1016/j.paid.2011.04.019

Kung, F. Y. H. and Scholer, A. A. (2020) 'The pursuit of multiple goals', Social and Personality Psychology Compass, 14(1), pp. 1-14. doi: 10.1111/spc3.12509.

Lewis, J. R. (1991). Psychometric evaluation of an after-scenario questionnaire for computer usability studies: Thes ASQ. SIGCHI Bulletin, 23(1), 78-81. 
Locke, E. A. and Latham, G. P. (2019) 'The development of goal setting theory: A half century retrospective.', Motivation Science, 5(2). doi: 10.1037/mot0000127.

Locke, E. A. and Latham, G. P. (1990) A theory of goal setting and task performance. Englewood Cliffs, NJ, USA: Prentice Hall.

Locke, E. A. and Latham, G. P. (2002) 'Building a practically useful theory of goal setting and task motivation: A 35-year odyssey', American Psychologist, 57(9), pp. 705-717. doi: 10.1037/0003-066X.57.9.705.

Louro, M. J., Pieters, R. and Zeelenberg, M. (2007) 'Dynamics of Multiple-Goal Pursuit', Journal of Personality and Social Psychology, 93(2). doi: 10.1037/0022-3514.93.2.174.

Neal, A., Ballard, T. and Vancouver, J. B. (2017) 'Dynamic Self-Regulation and Multiple-Goal Pursuit', Annual Review of Organizational Psychology and Organizational Behavior. doi: 10.1146/annurev-orgpsych-032516-113156.Louro, M. J., Pieters, R. and Zeelenberg, M. (2007) 'Dynamics of Multiple-Goal Pursuit', Journal of Personality and Social Psychology, 93(2). doi: 10.1037/0022-3514.93.2.174.

McCrae, R. R., \& Costa, P. T. (1987). Validation of the Five-Factor Model of Personality Across Instruments and Observers. Journal of Personality and Social Psychology, 52(1), 81-90. https://doi.org/10.1037/0022-3514.52.1.81

Morisano, D. (2013) 'Goal setting in the academic arena', in Locke, E. A. and Latham, G. P. (eds) New developments in goal setting and task performance. New York, NY: Routledge/Taylor \& Francis Group, pp. 495-506. Available at: http://search.ebscohost.com/login.aspx?direct=true\&db=psyh\&AN=2013-00428-030\&site=ehost-live.

Mora-Villalobos, C. R., Oreopoulos, P. and Petronijevic, U. (2017) 'Goal Setting, Academic Reminders, and College Success: a Large-Scale Field Experiment', Uniagraria, Volumen 5. Available at: http://www.nber.org/papers/w23738\%0Ahttps://www.socialscienceregistry.org/trials/810\%0Ahttp://www.nber.org/da ta-appendix/w23736.

Sheldon, K. M. (2014). Becoming oneself: The central role of self-concordant goal selection. Personality and Social Psychology Review, 18(4), 349-365.

Schippers, M. C. et al. (2020) 'Writing about personal goals and plans regardless of goal type boosts academic performance', Contemporary Educational Psychology. Elsevier, 60(November 2019), p. 101823. doi: 10.1016/j.cedpsych.2019.101823.

Vancouver, J. B. and Austin, J. T. (1996) 'Goal constructs in psychology: Structure, process, and content.', Psychological Bulletin, 120(3), pp. 338-375.

Vansteenkiste, M. et al. (2004) 'Motivating Learning, Performance, and Persistence: The Synergistic Effects of Intrinsic Goal Contents and Autonomy-Supportive Contexts.', Journal of Personality and Social Psychology, 87(2), pp. 246-260. doi: 10.1037/0022-3514.87.2.246.

Weber, F. (2019) 'Goal Trees as Structuring Element in a Digital Data-Driven Study Assistant', in Sampson, D. G. et al. (eds) 16th International Conference on Cognition and Exploratory Learning in the Digital Age (CELDA 2019). Cagliari, Italy: IADIS Press, pp. 413-416.

Werner, K. M. et al. (2016) 'Some goals just feel easier: Self-concordance leads to goal progress through subjective ease, not effort', Personality and Individual Differences, 96. doi: 10.1016/j.paid.2016.03.002.

Zimmerman, B. J. (1989). Models of Self-Regulated Learning and Academic Achievement (pp. 1-25). https://doi.org/10.1007/978-1-4612-3618-4_1

Zimmerman, B. J. (1990). Self-regulating academic learning and achievement: The emergence of a social cognitive $\begin{array}{lllll}\text { perspective. } & \text { Educational } & \text { Review, } & \text { 2(2), } & 173-201 .\end{array}$ http://www.jstor.org.libraryproxy.griffith.edu.au/stable/pdfplus/23359581.pdf 